\title{
El silencio como discriminación discursiva de lo indígena Análisis socio-cognitivo de libros escolares mexicanos ${ }^{1}$
}

\author{
Alba Nalleli García Agüero \\ University of Bern
}

\section{Introducción}

La educación escolar, además de instruir, tiene entre sus principales objetivos moldear el imaginario colectivo, formar identidades, unificar la ideología, reproducir el sistema y crear lealtad hacia el gobierno en turno. Los libros escolares han sido una herramienta eficaz para alcanzar estos objetivos (Gilbert 2003; Cabanel 2007; Narvaja de Arnoux 2008).

En México, los libros de texto ofrecidos por el gobierno de manera gratuita (Libros de Texto Gratuitos, a partir de aquí LTG) aparecieron en I960. Uno de sus principales objetivos fue el de reforzar la cohesión ideológica en concordancia con los intereses del Estado. Para ello, se recurrió a la formación de un sentimiento de identidad nacional y a la construcción discursiva y difusión de un prototipo de «mexicano». Aun cuando en los primeros libros despunta la intención de incluir al indígena dentro del modelo identitario, esta figura no logra estar dentro de la categoría por motivos ideológicos. Las preguntas a las que queremos responder en este artículo son, en primer lugar, ¿qué mecanismos textuales e icónicos son utilizados en la construcción de la figura del indígena en contraste con la del modelo prototípico de mexicano en los primeros LTG? y, en segundo lugar, ¿cuáles fueron las razones por las

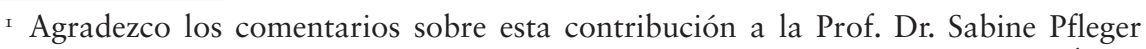
(UNAM), Prof. Dr. Yvette Bürki (Universität Bern), así como del Lic. Miguel Ángel García Aguirre.

Cómo citar este capítulo:

García Agüero, A. N. 2019. "El silencio como discriminación discursiva de lo indígena Análisis socio-cognitivo de libros escolares mexicanos”. In: Françoise Sullet-Nylander, María Bernal, Christophe Premat \& Malin Roitman (eds.). Political Discourses at the Extremes. Expressions of Populism in Romance-Speaking Countries. Stockholm Studies in Romance Languages. Stockholm: Stockholm University Press, pp. 20I-222. DOI: https://doi.org/IO.I6993/bax.j. License: CC-BY 
que el indígena fue silenciado discursivamente en las siguientes generaciones de LTG?

Aunque parezca que los libros escolares no forman parte de los discursos políticos, en muchos casos, como hemos apuntado arriba, han contribuido a impartir los conocimientos oficiales que los gobiernos necesitan inculcar en los ciudadanos. El hecho de que en México los LTG sean entregados desde I960 de manera gratuita y sean obligatorios para todos los niños mexicanos, los convierte en una herramienta de dominación ideológica utilizada por el gobierno mexicano -el cual fue de derecha hasta 2018- para diseñar un modelo compartido de nación.

En este estudio tomaremos en consideración tres generaciones de LTG que correspondieron a tres reformas educativas a partir de las cuales se modificaron los planes de estudio y los materiales escolares. Los manuales analizados, pertenecientes a la primera generación son Mi libro de primer año y Mi cuaderno de trabajo de primer año (I960). De la segunda generación de libros tomamos en cuenta Español primer grado y Ciencias Sociales primer grado (1972), Mi libro de primero. Parte I y Parte II (1984). Como parte de la tercera generación analizamos el Libro integrado primer grado (I994).

Debido a su potencial como transmisores de ideologías, los materiales educativos han sido objeto de estudio de diferentes fenómenos sociales entre los que se encuentran la conformación y representación de identidades nacionales (Gilbert 2003; Cabanel 2007; Narvaja de Arnoux 2008). Aunque los estudios anclados en perspectivas lingüísticas son aún escasos, recientemente se observa un interés por abordar el estudio de libros escolares desde un enfoque crítico discursivo (Atienza Cerezo 2007; Chine 20II; Taboada 20II; Rodríguez Gómez 20II; D’Alessandro 20I4; Oteíza 20I4; Zullo 20I4).

Así como las investigaciones anteriores, la presente contribución se enmarca dentro del Análisis Crítico del Discurso. Más específicamente, inscribimos este trabajo en los Estudios Críticos del Discurso (CDS, por sus siglas en inglés), los cuales ponen especial interés en ofrecer herramientas de análisis que permitan demostrar y explicar el posible impacto cognitivo de determinadas estrategias discursivas y los objetivos sociales y políticos que se buscan a través de ellas². Uno de los principales representantes de los CDS es Teun van Dijk, quien ha desarrollado un modelo socio-cognitivo (cf. van Dijk I985, 2000, 2002, 2008) sobre el

${ }^{2}$ Sobre la postura epistémica de los CDS defendida por van Dijk (año), cf. http:// www.discourses.org/projects/cda/ 
cual nos basamos para tratar el tema de la construcción del esquema de identidad grupal. Así pues, a diferencia de los estudios arriba citados, la novedad de este análisis de tipo cualitativo reside en la incorporación de herramientas de análisis de la Lingüística Cognitiva (Lakoff \& Johnson I980; Lakoff I987) y de la semiótica social (Kress \& van Leeuwen I996) que nos ayudarán a responder a nuestras preguntas de investigación. En otras palabras, este marco teórico de cariz socio-cognitivo nos servirá para demostrar cómo se manifiestan en los libros ciertas estrategias lingüísticas e icónicas y cuál es el impacto cognitivo que estas tienen en la fijación de representaciones ideologizadas como lo son la figura del indígena y la del mexicano prototípico.

\section{El carácter socio-cognitivo de la identidad}

La identidad es un fenómeno social y cognitivo activamente construido, negociado y resistido a través del discurso (Benwell \& Stokoe 2006: 3-4). La identidad de un individuo está conformada por varias facetas, las cuales se despliegan de acuerdo a la situación interaccional y a los objetivos de los hablantes (Goffman I959). Una de estas facetas es la identidad social. Dentro de la psicología social, Tajfel (I98I: 225) define la identidad social como "[...] that part of the individual's self-concept which derives from his knowledge of his membership in a social groups (or groups) together with the value and emotional significance attached to that membership». Dicho de otro modo, este conocimiento del individuo sobre su pertenencia a un grupo es un reconocimiento, es decir, aceptación de él mismo como miembro de un colectivo con el que se identifica. Tal admisión proviene de la internalización y aceptación de ciertas ideas. En efecto, van Dijk (I998: I28) afirma que la identidad grupal está fundamentada en una ideología, es decir, en «axiomas» de creencias sociales. En este sentido, la identidad (tanto grupal como individual) comprende una dimensión social, porque se construye a partir de la interacción con otros (Goffman 1959) y es elaborada y negociada a través del discurso (Benwell \& Stokoe 2006; De Fina 2007); pero también posee una dimensión cognitiva porque se cimienta en creencias personales y compartidas (van Dijk I998).

Así pues, van Dijk (I998: I2I) afirma que las ideologías constituyen «the basis of group identity, that is, the fundamental propositions that pertain to more or less stable evaluations about 'our' group's membership criteria, activities, goals, norms and values, social resources and especially our position in society and the relations with special other groups». 
De acuerdo con el lingüista holandés, tales creencias están organizadas en un esquema de autorrepresentación grupal estructurado por ciertas categorías fijas, las cuales representan los aspectos esenciales del grupo, a saber: propiedades definitorias, actividades, objetivos, valores, relaciones con otros grupos y recursos (van Dijk I998: 69-70, I29; 2000: I7). En otras palabras, la ideología que sostiene la identidad de un grupo está organizada en un esquema que encierra creencias, conocimientos y actitudes que permiten a los integrantes de un colectivo responder a las preguntas sobre quiénes son, cómo son, cuáles son los criterios para pertenecer a su grupo, cuáles son los objetivos y valores comunes, y cómo se relaciona su grupo con otros colectivos.

Este esquema de autorrepresentación grupal constituye un Modelo Cognitivo Idealizado (MCI) noción introducida en la Lingüística Cognitiva por George Lakoff (I987: 68-7I). Los MCI son representaciones mentales abstractas y generalizadoras, es decir, conocimientos interrelacionados a partir de los cuales entendemos y formulamos conceptos, pero son idealizados en tanto que suelen no ajustarse a la realidad. Existen conceptos complejos o abstractos formados por la aglutinación de diferentes modelos cognitivos (o dominios, según Taylor I995: I42), los cuales son llamados Cluster Models (Lakoff I987: 74).

Una noción tan compleja y abstracta como la de identidad nacional puede ser conceptualizada a partir de un conglomerado de modelos mentales (Lakoff I987) o categorías cognitivas (Lakoff I987: 69; van Dijk I998) que son asumidas por el colectivo nacional.

\section{El modelo mental del prototipo de mexicano en las tres generaciones de LTG}

Los LTG han contribuido a la consolidación del esquema mental compartido de la identidad mexicana. A través de ellos, el gobierno ha difundido las propiedades axiomáticas que componen la autorrepresentación grupal, es decir, la ideología que define «el ser mexicano». De acuerdo a nuestro análisis basado en la Lingüística Cognitiva, estas creencias se han transmitido a partir de ocho modelos o categorías mentales que aparecen en mayor o menor medida en las tres generaciones de libros: la familia, el territorio, la patria, la historia, el civismo, la cultura, el fenotipo y «el otro».

El modelo mental de la familia comprende a la madre, al padre y a los hijos (en muy pocas ocasiones aparecen los abuelos y los tíos). Todas las generaciones de libros representan a los padres como responsables de los 
cuidados de los hijos, sin embargo en la primera generación estas figuras adquieren otras propiedades que se difuminan más tarde: la madre es la principal responsable de las labores del hogar y está supeditada al padre, el cual tiene la responsabilidad del mantenimiento económico de la familia. Los hijos, por su parte, ayudan y aman a sus padres de manera religiosa, actitud que desaparece a partir de la segunda generación de libros.

El modelo del territorio indica que México es la región geográfica donde nacieron y viven los mexicanos. Tal modelo se despliega en todos los manuales. El modelo de la patria implica que México es el hogar que alberga y protege a los mexicanos y que a su vez estos honran, defienden, aman y trabajan por ella. Este segundo modelo aparece constantemente en la primera generación, mientras que en el resto de los libros se le hace alusión solo a través del Himno Nacional y la bandera de México. El modelo histórico de la primera generación propone que los mexicanos tienen un pasado mítico forjado por los ancestros fundadores y los héroes nacionales cuyas acciones ayudaron a construir la patria. Sin embargo, a partir de los libros de los setenta este modelo cambia radicalmente: ya no serán los héroes nacionales los que propicien los cambios históricos, sino que estos se deberán a las acciones de las fuerzas sociales. El modelo cívico, indicador de los valores morales y comportamientos que el mexicano pone en acto, es aludido con mucha insistencia en los libros de I960; sin embargo, se desdibuja drásticamente en la segunda generación. Es decir, mientras que los primeros manuales proponen que el mexicano es solidario, honrado, trabajador, respeta y ama al prójimo, es valiente y heroico ( $c f$. Libro de Lectura, a partir de aquí LL, I960: I70-I7I; I82-I83), los libros de los setenta y ochenta solo presentan una alusión a la ayuda mutua como un valor universal pero no la adjudican al comportamiento de los mexicanos. La propiedad cívica se retoma de manera un poco más clara en la última generación aunque tampoco se abren campos mentales que hagan pensar esta cualidad como distintiva de la comunidad mexicana. El modelo cultural supone que el mexicano participa en determinadas prácticas sociales como ceremonias y celebraciones, que conoce el folklor nacional y consume comida mexicana. Según nuestro análisis, el elemento cultural es más marcado en los primeros libros, disminuye en la siguiente generación y se retoma con un mayor número de ejemplos en la última. El modelo fenotípico es planteado únicamente de manera icónica. Los niños de las imágenes, tanto en los dibujos como en las fotografías presentan en su mayoría las mismas características: son mestizos de piel morena clara, pelo oscuro y portan vestimenta adecuada a la ciudad. 
Aparecen también, pero en pocas ocasiones, imágenes de niños con una tez un poco más oscura o con vestimenta que corresponde a la usada en el campo. Uno de los procesos que comprende la autocategorización grupal es la determinación del otro en oposición al nosotros (van Dijk 20II). El modelo del otro planteado por los primeros manuales comprende al indígena, del que hablaremos a continuación, y al español, representado negativamente por los conquistadores del siglo XVI. Estas figuras, así concebidas desaparecen en los libros posteriores.

En todos los libros, la categoría de mexicano es construida paulatinamente a lo largo de las lecturas, es decir, se van planteando los modelos cognitivos con un orden específico, de modo que los niños puedan forjar el MCI a partir de conocimientos para él familiares. Así, se comienza por el reconocimiento de la identidad yo-niño; luego se pasa al ámbito de la familia, que posteriormente servirá como metáfora de patria; se prosigue con el modelo cívico; se arriba al modelo cultural para culminar con modelos más complejos como los de la patria y la historia.

\section{El modelo cognitivo idealizado del indígena en la primera generación de LTG}

Los modelos cognitivos de la familia, el territorio, la patria, la historia, el civismo, la cultura, el fenotipo y «el otro» contienen las creencias que sustentan la identidad colectiva y dan respuesta a las preguntas sobre lo que significa pertenecer al grupo. A partir de la reiteración ${ }^{3}$ continua de las características arriba citadas, los libros establecen el prototipo de mexicano.

A pesar de que en México la población indígena ha representado un porcentaje significativo de la población total ( $10.4 \%$ en I960; $7.8 \%$ en I970; $7.6 \%$ en I990) ${ }^{4}$, el MCI de mexicano que presentan los libros de

\footnotetext{
3 La psicóloga cognitiva Eleanor Rosch (I978), cuya teoría de prototipos ha sido acogida dentro de la LC, demostró que mientras más prototípico fuera un elemento, más alta era su frecuencia y el orden de mención en el discurso. Observó también que el orden y rapidez de aprendizaje de un elemento por parte de los niños dependía de la mayor o menor cercanía que este tuviera con el prototipo. Finalmente, comprobó que la velocidad con la que un elemento se asignaba a una categoría dependía también de su centralidad dentro de la categoría (Rosch I978: I3-I4).

${ }^{4}$ Fuente: http://cedoc.inmujeres.gob.mx/documentos_download/I 00782 .pdf. Aunque los porcentajes provienen de fuentes oficiales, es preciso decir que no se puede contar con cifras precisas, ya que siempre se ha subestimado la población indígena de México. Navarrete Linares (2008: I4) explica que antes del año 2000 solo se había considerado como indígenas a los hablantes de una lengua indígena
} 

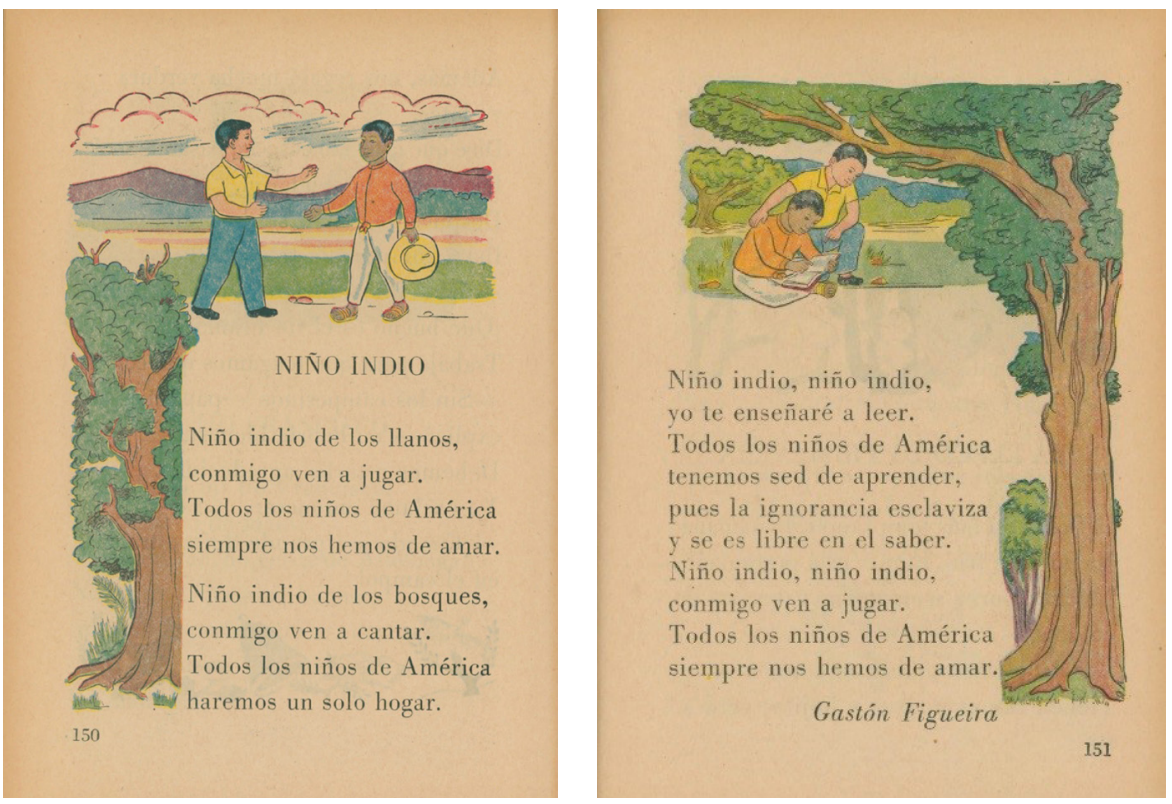

Fig. 1a-b. Modelos cognitivos constituyentes de la figura del indígena (LL, pp. I 50-I5I) " Niño indio ». Mi libro de primer año. I962. Ilustradores: Oswaldo Barra, Alberto Beltrán, Jorge Best, Ángel Bracho, Antonio Cardoso, Enrique Carreón, Andrea Gómez, Rafael Jarama, Juan Madrid, Manuel Salinas, Rosendo Soto, Raúl Velázquez y Mariana Yampolsky. Public domain / Libros de Texto Gratuitos. CONALITEG / SEP. https://historico.conaliteg.gob.mx/content/restricted/libros/carrusel.jsf?idLibro=344

texto no ha comprendido este sector de la sociedad. Si bien la primera generación de libros editada de I960 a I972 habla del indígena en sus últimas páginas, lo muestra como una figura cuyas características no corresponden con las del mexicano prototípico. En efecto, Mi libro de primer año crea dos MCI paralelos, uno para el mestizo (mexicano prototípico) y otro para el indígena.

Como en el caso del MCI de mexicano, el del indígena se construye mediante ciertos modelos cognitivos evocados por el texto y las imágenes (Fig. I). Tales modelos son la vida rural («Niño indio de los llanos»;

y se excluía a los menores de 5 años por no ser hablantes fluidos de sus idiomas. A partir del 2000, para subsanar esa subestimación se ha incluido a los menores de 5 años que viven en hogares donde uno de los padres o abuelos habla una lengua indígena. Además, se ha añadido el criterio identitario, esto es, se ha considerado dentro de la población indígena a aquellos que se consideren como tales. 
«Niño indio de los bosques»); el modelo del territorio («todos los niños de América»); el modelo del conocimiento-ignorancia ("yo te enseñaré a leer»; "tenemos sed de aprender, pues la ignorancia esclaviza y se es libre en el saber», LL, I960: I72-I73). Además, visualmente se evoca el modelo fenotípico, el cual contrasta con el del prototipo: se observa un niño cuyo color de piel es más oscuro, viste pantalón de manta, sandalias, camisa de cuello semialto e incluso lleva un tipo de peinado específico.

Debido a que el manual está dirigido a niños, las imágenes juegan un papel muy importante para la transmisión de conocimientos. La figura del indígena está representada por un niño indio que aparece en cuatro ocasiones, tres de las cuales es mostrado acompañado del mestizo prototípico. Según la semiótica social (Kress \& van Leeuwen 2006), todos los elementos que componen la imagen, así como el lugar donde están posicionados, connotan significados abstractos como emociones, relaciones sociales, relaciones de poder, etc. Por lo tanto, la colocación de las figuras del mestizo y del indígena en el espacio visual resulta determinante para la construcción y concepción de ambos MCI.

En las tres ocasiones en que aparecen los dos personajes juntos, el niño indígena es colocado a la derecha y/o por debajo del niño prototípico (Figs. I, 2, y 3). Esta colocación tiene implicaciones cognitivas importantes, ya que debido a nuestra experiencia corpórea y cultural, lo que está arriba lo relacionamos con lo inalcanzable, lo ideal, lo bueno. Todo lo contrario expresa la orientación abajo (Lakoff y Johnson I980: $5 \mathrm{I}$ ). Asimismo, por nuestra experiencia de lectura en el mundo occidental, la orientación a la izquierda representa lo conocido, lo familiar mientras que la orientación derecha representa lo nuevo, lo desconocido, lo problemático y refutable (Kress \& van Leeuwen 2006: I 8 I-I 85 ).

Así pues, en la única generación de libros donde aparece el indígena, este se encuentra en una colocación inferior al niño prototípico que, al estar por encima, se le relaciona metafóricamente con lo ideal. Además, la posición que adopta este niño expresa una actitud paternalista hacia el niño indígena, sugiriendo con ello la inferioridad del último (Figs. I y 2).

A nivel lingüístico, al indígena no se le da agentividad dentro de la oración, sino que actúa como paciente. Por ejemplo, en la lectura «Niño indio»(Fig. I), recibe los efectos de la acción del niño prototípico: «Niño indio, niño indio, yo te enseñaré a leer» (LL I960: I 5 I). De esta manera, el niño más blanco se identifica mediante el pronombre de primera persona yo evidenciando y enfatizando al agente que actúa sobre el paciente, lo cual se refuerza además por medio de la imagen que, como se mencionó arriba, sugiere la invalidez del indígena. 


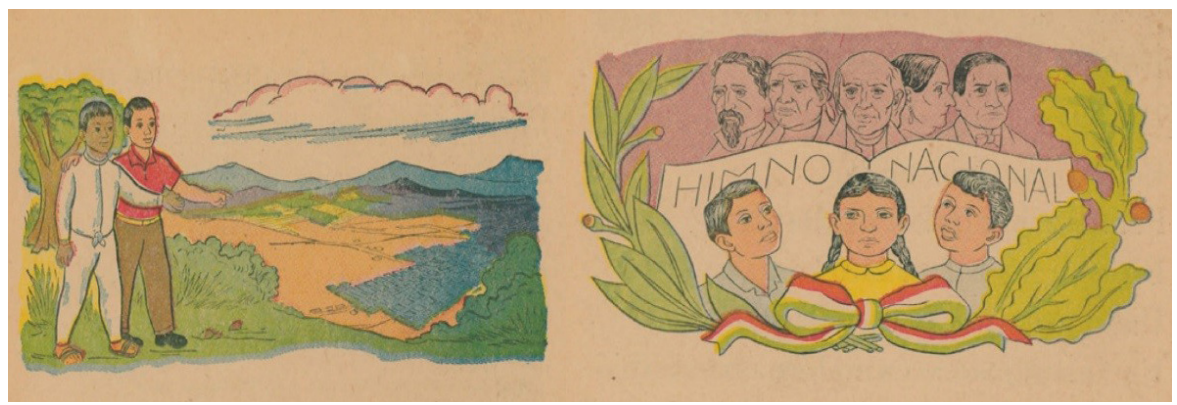

Fig. 2 y 3. Fig. 2: Colocación del indígena en el espacio visual. Actitud paternalista del mexicano prototípico (LL, p. I72). "La patria ". Mi libro de primer año. I962. Fig. 3: Colocación del indígena en el espacio visual con respecto al mexicano prototípico (LL, p. I80). «El himno nacional ». Mi libro de primer año. I962. (Fig 2 y 3): Ilustradores: Oswaldo Barra, Alberto Beltrán, Jorge Best, Ángel Bracho, Antonio Cardoso, Enrique Carreón, Andrea Gómez, Rafael Jarama, Juan Madrid, Manuel Salinas, Rosendo Soto, Raúl Velázquez y Mariana Yampolsky. Public domain / Libros de Texto Gratuitos. CONALITEG / SEP. https://historico.conaliteg.gob.mx/content/restricted/libros/carrusel.jsf?idLibro $=344$

En suma, las características que conforman el MCI de indígena comprenden un individuo del campo, ignorante, vulnerable, indefenso, que vive también en territorio americano, de piel más oscura, que viste de un modo particular y que es inferior al prototipo.

Lingüísticamente, la primera generación de libros pareciera mostrar la voluntad de incluir al niño indígena dentro de la categoría de mexicano, sin embargo, este objetivo no es logrado. Esta intención se puede observar en el uso del deíctico inclusivo nosotros usado por uno de los personajes de la lectura «La Patria», cuyas características corresponden a las del MCI del indígena (Fig. 2): «En mi pueblo pensamos lo mismo. La tierra, nuestras cosas y nosotros formamos la patria» (LL I960: I73). A pesar de que en esta lectura -por única ocasión- se le da voz al indígena para sugerir que también es parte del colectivo nacional, termina siendo excluido: mientras que a los demás personajes se les asigna un nombre (Héctor, Raúl, María, Luis), el personaje que enuncia esta expresión es identificado solo como "otro compañero [que] viene de un pueblo lejano» (LL I960: I72). Así, se abre el modelo de la lejanía, de lo extraño, de lo no identificable y con ello el indígena queda desubjetivizado. Un ejemplo a nivel icónico del intento fallido de incluir al indígena 
se encuentra en las páginas dedicadas al Himno Nacional donde se ven tres niños, dos de ellos ostentan características del mexicano prototípico mientras que, nuevamente, a la derecha de la imagen, en el lado de lo desconocido, se encuentra el niño indígena (Fig. 3). Todos estos contrastes a nivel icónico y verbal entre el niño prototípico y el indígena hacen que se conceptualice a este último como «el otro».

\section{El silencio: la desaparición discursiva del indígena en los LTG}

El discurso de los primeros libros que fueron establecidos como gratuitos y obligatorios en I960 construyó un modelo de mexicano que persistió más tarde en los materiales publicados entre I972 y I994. Aunque la primera generación de libros comprendió al indígena en su discurso, este nunca figuró dentro del esquema identitario y, a partir de la edición de 1972, desapareció del panorama discursivo.

De acuerdo con Fairclough (1995: 2), cada propiedad del texto es potencialmente ideológica, desde el vocabulario, la sintaxis, las convenciones de cortesía, el estilo, hasta la ausencia de elementos en el texto. En este sentido, la desaparición de un elemento textual tiene también un significado e implicaciones importantes para la percepción del discurso, por tal motivo, la elisión del indígena en los LTG merece nuestra atención.

El indígena es silenciado discursivamente en los LTG, e indudablemente, este hecho ha tenido repercusiones en la conformación del modelo mental de identidad mexicana. Pero, ¿cuáles son los motivos de este silencio discursivo? Las razones por las que desaparece el indígena son de naturaleza político-ideológica.

Las ideologías de los diferentes regímenes, que legitimaron y reprodujeron el sistema y que conformaron del esquema mental de identidad nacional, se ubicaron en contextos socioeconómicos diferentes y cambiaron según las circunstancias históricas. Los LTG son espejo de dichos cambios. La primera generación de libros surgió de la necesidad de responder al crecimiento industrial y económico alentado por el programa desarrollista del presidente Adolfo López Mateos (I958I964). La reforma educativa promulgada durante su mandato sentó las bases ideológicas a partir de las cuales serían escritos los manuales. La reforma buscaba alcanzar los «grandes propósitos nacionales», es decir, mitigar las desigualdades y formar una nación por medio de la unidad de todos los mexicanos (Torres Barreto 2007: 338). Específicamente, se buscaba fomentar el amor a la patria, la conciencia de solidaridad 
internacional, la independencia y la justicia. No se puede olvidar que el telón de fondo en el que fueron realizados los libros eran el contexto de la posguerra; el mundo bipolar (bloque capitalista $v s$ bloque socialista) representado por la Guerra Fría; el crecimiento poblacional y urbano que vivió el país en los sesenta (aunque el sector rural seguía teniendo una fuerte presencia en la vida cotidiana y en la economía nacional); la creciente inversión estadounidense; y la reciente Revolución Cubana que había ganado muchos simpatizantes en México y había sido la causa por la que el gobierno de EE. UU. desarrolló la política «Alianza para el Progreso», instituida por el gobierno mexicano. Pero tampoco se deben olvidar los ideólogos y productores textuales: por un lado, Jaime Torres Bodet, dos veces secretario de educación (I943-I946 y 1958-I964) y director general de la UNESCO (I948-I952), cuyas ideas y decisiones tuvieron gran impacto en el ámbito educativo. Fue autor de la reforma al artículo constitucionals que concierne la educación en México, diseñador del Plan nacional para el mejoramiento y la expansión de la educación primaria en México, y promotor de los libros que por primera vez serían gratuitos y obligatorios para todos los niños mexicanos (LTG). Por otro lado, el escritor y político elegido como director de la institución que se encargaría de elaborar los LTG (CONALITEG), Martín Luis Guzmán. Su participación en la Revolución mexicana como asesor político del general Francisco Villa marcó también los primeros libros: la ideología revolucionaria, defensora del reconocimiento de las garantías sociales de campesinos y obreros y trasmisora de una serie de símbolos patrios a los que se atribuía la esencia de la mexicanidad, se puede observar desde las portadas de los manuales ${ }^{6}$.

Ante las circunstancias históricas que dictaban el fortalecimiento de una identidad nacional muy precisa, el ideario revolucionario patriótico

${ }_{5}$ En 1946 Torres Bodet promovió una reforma que modificó significativamente el contenido del artículo $3^{\circ}$ constitucional (artículo que establece los lineamientos de la educación en México). Con dicha reforma se confirmó el control del Estado sobre la educación, el laicismo como principio educativo, pero, además, se retomó del enfoque positivista y se introdujeron los conceptos de nacionalismo, democracia, mexicanidad y solidaridad internacional como metas del sistema educativo (Melgar Adalid I998: 466).

${ }^{6}$ Es de señalar que el general Francisco Villa, uno de los héroes nacionales de la Revolución agrarista de I9Io, no se reivindicaba como indígena y tanto menos lo hacía su ejército, a diferencia del otro general paradigmático, Emiliano Zapata, jefe del ejército Libertador del Sur que estaba integrado por miles de indígenas que se reconocían y se reivindicaban como tales. 
y las ideas de respeto y cordialidad hacia otros pueblos para mantener la paz, derivadas de la experiencia de Torres Bodet en la UNESCO, justifican el lugar discursivo que se le dio al "niño indio», como es denominado en esta generación de libros.

La segunda generación de LTG (I972-I994) surge a raíz de una reforma educativa llevada a cabo por el presidente Luis Echeverría Álvarez en 1972. La nueva propuesta educativa fue una de las medidas tomadas para tratar de calmar el gran descontento social que había dejado la feroz represión del movimiento estudiantil de $1968^{7}$ a cargo el mandatario anterior Gustavo Díaz Ordaz. Además de la reforma educativa, otra de las estrategias que usó el gobierno de Echeverría (también de derecha) para intentar convencer a la sociedad mexicana de que su mandato representaba un claro rompimiento con la gubernatura precedente fue el diseño de una política exterior sin precedentes en México (Shapira I978). Echeverría hizo grandes esfuerzos para promover la solidaridad entre los países del Tercer Mundo con el fin de cambiar la estructura del sistema económico internacional y romper la dependencia económica principalmente con EUA. Esta medida de corte populista le serviría para legitimar su régimen mediante el llamado pluralismo ideológico. En efecto, Echeverría asistió a innumerables foros en los que fungió como defensor de los países tercermundistas, quienes teniendo características ideológicas, culturales y sociales distintas deseaban reconfigurar el sistema económico internacional (Lezama Juárez s/f). Finalmente, otra de las estrategias que atrajeron la atención de los sectores que el mandatario estaba interesado en convencer (universitarios, intelectuales y otros personajes del campo progresista) fue la de establecer una estrecha relación con el gobierno socialista de Salvador Allende, acción que resultó un tanto provocadora para EUA

7 El Movimiento del 68 fue una movilización inicialmente estudiantil secundada por amplios sectores populares que surgió en julio de I968 como reacción a las violentas represiones que estudiantes habían sufrido por parte del gobierno de Díaz Ordaz. La protesta se concretó en demandas sociales de democracia y libertad, con lo cual ganó una inmensa cantidad de seguidores. Las manifestaciones y actos de protesta amenazaban la estabilidad social así como la imagen de México, sobre todo cuando el mundo tenía la mirada puesta en el país por las Olimpiadas que se inaugurarían el 2 de octubre. Ante esta situación, el presidente Díaz Ordaz (con su sucesor Echeverría Álvarez a la cabeza de la secretaría de gobernación) decidió exterminar el movimiento mediante una represión armada el mismo día de la inauguración de las Olimpiadas. Hasta la fecha no se conoce el número exacto de las víctimas, principalmente estudiantes asesinados y desaparecidos ese día. 
pero que para la izquierda mexicana sería una señal de pluralismo ideológico y de apertura democrática (Lezama Juárez s/f).

La reforma educativa, los nuevos libros y las políticas demagógicamente progresistas y populistas que adoptó Echeverría calmaron los ánimos sobre todo de una parte del sector intelectual, directamente afectado e indignado por la represión del 2 de octubre de I968.

El reajuste ideológico que necesitaba el nuevo gobierno se vio reflejado en los LTG: la visión nacionalista y heroica de los libros de los sesenta cedió el paso a una de tipo «tercermundista». En efecto, la visión «hacia adentro» que se observa en la primera generación de libros corresponde con la política de aquel periodo de tipo aislacionista que desvinculó la economía del país del entorno internacional con el objetivo de propiciar el crecimiento interno y la estabilidad económica. En contraste, en los libros de los años setenta se aprecia una visión «hacia fuera» que corresponde a la estratégica política exterior progresista que adoptó el gobierno para fomentar el desarrollo y la estabilidad del país (Shapira 1977).

A diferencia de los primeros libros, realizados por maestros de primaria, la elaboración de los libros de los setenta fue encargada a grupos de trabajo conformados por intelectuales e investigadores (historiadores, antropólogos, sociólogos, lingüistas) de las más reconocidas universidades mexicanas. El involucramiento de este sector en la producción de los LTG, así como los valores que proponía la pregonada apertura democrática y la visión tercermundista, fueron factores que contribuyeron a disminuir, en cierta medida, el descontento generado cuatro años atrás.

De esta manera, los libros de texto fueron concebidos desde un enfoque social, populista y tercermundista: los productores plasmaron una visión de la realidad en la que los cambios ya no se debían principalmente a la intervención de los héroes nacionales, sino a las acciones de las fuerzas sociales (Torres Barreto 2007: I 28), es decir, el pueblo se volvió protagonista y motor de los procesos históricos. Dicho enfoque, sin embargo, fue muy criticado por la derecha mexicana quien protestó contra los materiales educativos tachándolos de «marxistas» $\mathrm{y}$ «comunistas» (Villa Lever I988: I69-200).

Así pues, desde este enfoque que volteaba la mirada hacia otras naciones y que coincidía con la política del gobierno concentrado en establecer y consolidar relaciones internacionales con países subdesarrollados, una figura como la del indígena mexicano ya no cumple una función importante para el desarrollo de la identidad nacional. 

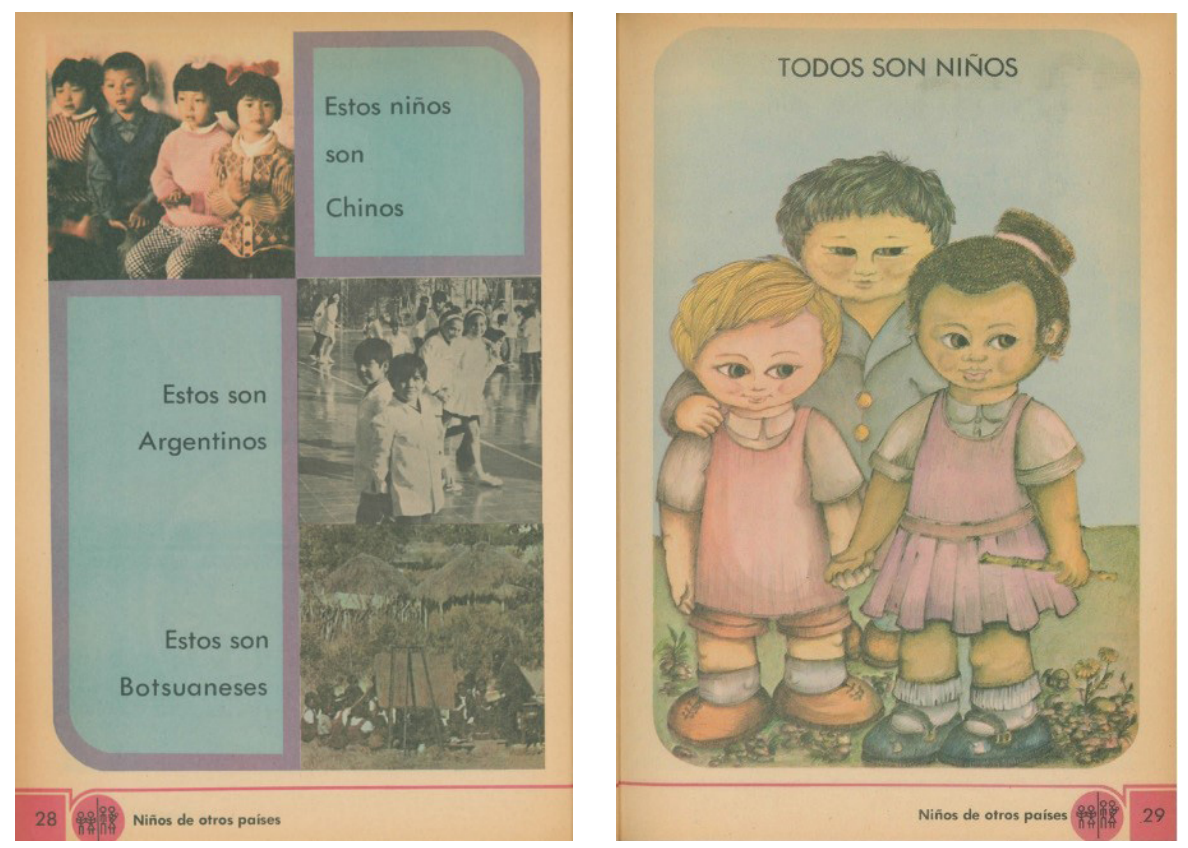

Fig. 4a-b Visión tercermundista de los LTG de 1972-I994. "Niños de otros países ». Ciencias Sociales. Primer grado. Ilustradores: Constanza Cervera, Miguel Ángel Espinoza, Silvana Cervera, Selva Riemann, Benjamín Orosco, José A. Consuegra, Ernesto Padrón, Kentha Wagner, Moisés Sierra, Francisco Sil, Antonio Zamora, Paul Robert, César Mora, Jack Seligson. Public domain / Libros de Texto Gratuitos. CONALITEG / SEP. https://historico.conaliteg.gob.mx/content/restricted/libros/carrusel.jsf?idLibro $=62$

La tercera y última generación (I994-2000) objeto de nuestro análisis comprende los materiales que se produjeron a partir de una nueva reforma educativa realizada en I992. Los nuevos LTG surgen en el marco de una abierta política neoliberal que apunta a la globalización capitalista. Diez años después de la aparición de la segunda generación de libros, el populismo, estandarte del echeverrismo, es desacreditado: a partir del gobierno de Miguel De la Madrid (I982-I988) y a raíz de la grave crisis económica que sufrió México en los ochenta, se atribuyó al populismo la deficiencia fundamental de la política gubernamental, lo cual sirvió para reprimir e ignorar demandas populares (Torres Barreto 2007: 107). El proceso de transformación del modelo nacional, de nacionalista-populista a neoliberal, comenzado por De la Madrid fue consolidada por el siguiente mandatario, Carlos Salinas de Gortari, 
quien impuso el esquema neoliberal globalizado en todos los ámbitos: económico, político, ideológico y educativo. Bajo la ideología neoliberal, la educación se concibe como una mercancía, como una empresa que debe mostrar su eficiencia -eficacia y rentabilidad en términos económicos- para la producción de capital (Caponi \& Mendoza 1997). Por esta razón, dicen Caponi y Mendoza (I997: 31), la educación se ajusta a un modelo tecnocrático: «se trata de entrenar mano de obra hábil pero acrítica, por ello, se jerarquizan los campos tecnológicos en detrimento de lo humanístico, ético y social».

El gobierno del presidente Ernesto Zedillo (I994-2000) no solo mantuvo, sino que amplió el modelo neoliberal. Durante su mandato se publicó la tercera generación de LTG, producto de la reforma educativa

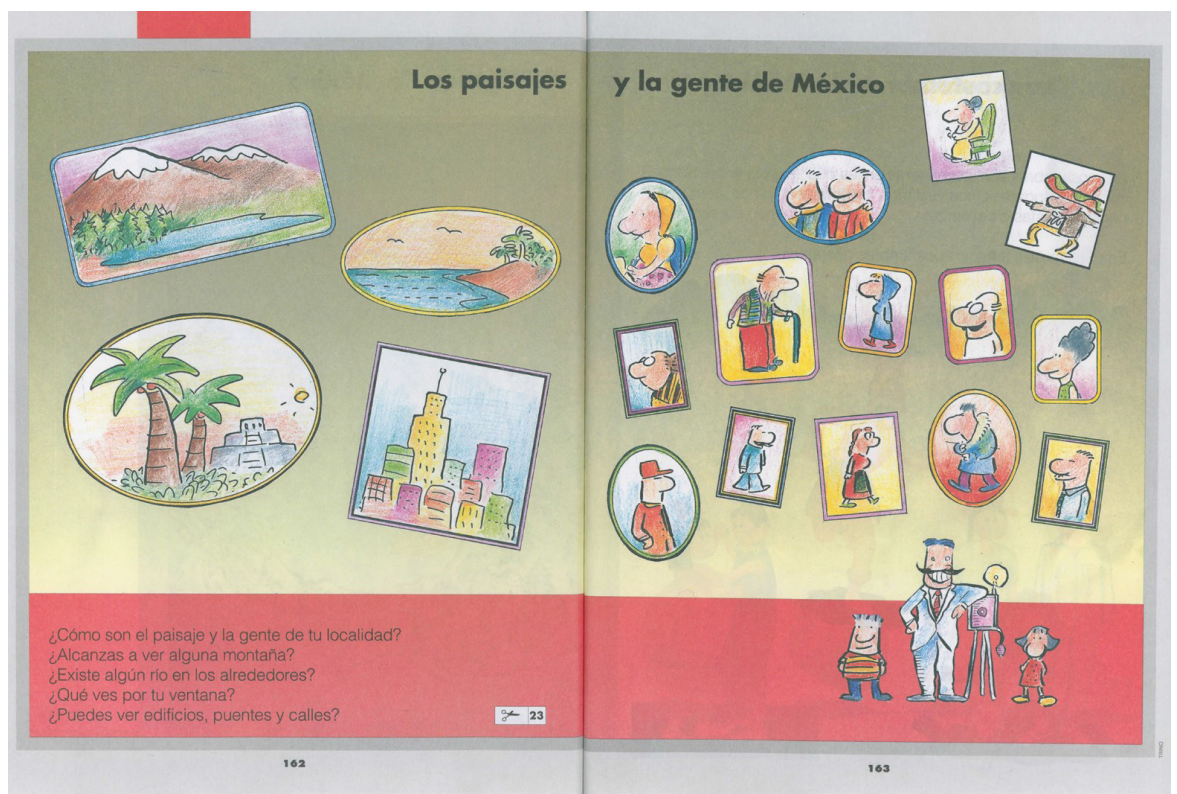

Fig. 5. Representación visual del modelo fenotípico en los LTG de I994. «Los paisajes y la gente de México ». I994. Libro integrado. Primer grado. Ilustradores: José Trinidad Camacho Orozco (Trino), Alain Espinoza mendoza, Hermilo Gómez Avelardi, Mauricio Gómez Morín Fuentes, María Elena Jiménez Huerta, María del Carmen Miranda Diosado, Leonid Nepomniachiy-Lívova, Felipe Saldarriaga Gutiérrez, Maribel Suárez Sitges, Felipe Ugalde, Trini Vangheluwe, Emilio Watanabe/Helia Bonilla. Public domain / Libros de Texto Gratuitos. CONALITEG / SEP. https://historico.conaliteg.gob.mx/content/restricted/libros/carrusel.jsf?idLibro $=\mathrm{I} 38$ 
de I992. Los ajustes a los planes y programas que marcaron los lineamientos para la producción de los libros pretendían incorporar a los individuos en la revolución de los conocimientos, resguardar valores y tradiciones de la nacionalidad y competir exitosamente con las naciones de vanguardia (Torres Barreto 2007: 326). Así pues, en los libros de texto de esta generación se observa el interés por fomentar el sentimiento de identidad nacional y una moral ciudadana pero en concordancia con el credo neoliberal; asimismo, se muestra un intento por legitimar las transformaciones económicas y sociales emprendidas por el gobierno salinista (Torres Barreto 2007: 326). Además, es llamativo el cambio radical que experimentó el discurso icónico, esto es, en esta generación desaparecen los dibujos de tipo realista y las fotografías y en cambio se privilegia el uso de la caricatura como medio ilustrativo. De este modo, se desdibuja el modelo fenotípico propuesto por los otros manuales y se plantea un individuo ambiguo, sin características específicas (Fig. 5).

En el marco de una política educativa de corte neoliberal que tiene como propósito legitimar el orden social, político y moral establecido; que mira hacia el exterior inculcando la competencia con otras naciones; que aumenta la distancia entre sectores sociales, una figura como la del indígena, no tiene lugar.

\section{6. Últimas reflexiones: la posición del indígena en la sociedad mexicana}

A pesar de que en México la población indígena ha representado un porcentaje significativo de la población total ${ }^{8}$, el indígena siempre ha tenido un lugar secundario dentro de la sociedad mexicana. Se le ha considerado como antítesis de modernidad y realmente nunca se le ha incluido en el proyecto nacional. No se ha reconocido ni respetado la identidad de los pueblos indígenas, al contrario, se les ha querido incorporar a la sociedad mexicana despojándolos de sus costumbres, sus lenguas, sus sistemas normativos, sus territorios en un afán de unificación nacional?.

${ }^{8}$ A nivel mundial, México ocupa el $6^{\circ}$ lugar en cuanto a existencia de culturas y lenguas indígenas vivas. Existen estados en los que la población indígena es muy densa, tal es el caso de Oaxaca. Según el censo de población realizado por el INEGI en el 2010, el estado ocupa el primer lugar nacional en número de pueblos indígenas y el $58 \%$ de la población oaxaqueña se considera a sí misma como indígena (García Aguirre 2013).

9 Esta situación de profunda discriminación y explotación de los pueblos indígenas se encuentra en la raíz de lo que fue el levantamiento armado indígena del Ejército 
El prejuicio racial ha sido parte implícita de la cultura mexicana desde la conquista. Hoy en día, dice Latapí (I998: I7I), el racismo sigue presente y permea todos los ámbitos sociales; se aprecia en las aspiraciones, los juicios, valores y conductas, el lenguaje, los insultos, los ideales de belleza y los imaginarios colectivos. Tal ideología racista, que margina al indígena, que lo ningunea, le roba agentividad, es decir, que lo desubjetiviza, ha sido fomentada por los medios de comunicación. Como hemos tratado de dilucidar, este racismo se encuentra también en los LTG y es fomentado tanto por el discurso icónico y verbal como por el silencio discursivo que omite al indígena.

Si bien algunos gobiernos mexicanos han demostrado cierto interés por los pueblos indios al ofrecerles una educación más acorde con sus identidades (mediante, por ejemplo, libros de texto en diferentes lenguas indígenas), es de resaltar que esta educación bilingüe y bicultural ha carecido de una planeación y métodos pedagógicos satisfactorios (Latapí I998: I73). A raíz de la rebelión indígena zapatista de $1994^{\text {I0 }}$,

Zapatista de Liberación Nacional (EZLN) el I de enero de I994, curiosamente el mismo día en el que el gobierno del presidente Salinas de Gortari firmaba el Tratado de Libre Comercio de Norteamérica (EUA-Canadá-México) con el cual se abrieron las puertas al neoliberalismo y la globalización.

ro El levantamiento armado indígena del EZLN (I de enero de I994) se da en un contexto sociopolítico mundial y nacional muy especial. Por un lado, la propia elección de Carlos Salinas de Gortari (a partir de aquí CSG) como presidente de la República (fines de I988) fue altamente cuestionada en su legitimidad, existiendo claros elementos que muestran que dicha elección fue producto de un descarado fraude electoral. Por el otro, CSG representó a lo largo de su administración sexenal (I988-I994) la imposición plena en México del modelo capitalista neoliberal mundial, expandido por Estados Unidos y sus aliados europeos, inmediatamente después de la caída final del bloque socialista encabezado por la extinta URSS, en I989, proceso que eufemísticamente fue denominado como «globalización». Siendo parte de una generación de jóvenes políticos educados en universidades norteamericanas, CSG impuso un modelo de desarrollo basado en la paternal rectoría del Estado que se avocó a la expansión y modernización de la infraestructura nacional, a la transformación gradualista de un México rural a un México urbano y al lento crecimiento del mercado interno; todo ello basado en un asistencialismo populista y el control político a toda costa.

Dos acciones tomadas por CSG en aras de esta «modernización» socioeconómica e integración al mercado mundial aceleraron el clandestino crecimiento del movimiento armado indígena: a) la contrarreforma al artículo $27^{\circ}$ constitucional símbolo fundamental del mayor logro alcanzado por la Revolución Mexicana agrarista de I9I7- que no sólo significó el término del reparto agrario sino que abrió al mercado las tierras de propiedad social (ejidos y bienes comunales indígenas) que hasta ese momento habían sido constitucionalmente invendibles, inembargables e imprescriptibles; y b) la discusión, elaboración y firma del Tratado de Libre Comercio de Norteamérica (EUA, Canadá y México) (TLCAN), mediante el cual 
el Programa de Desarrollo Educativo señaló la importancia de combatir en la educación cualquier forma de racismo y de reconocer que la riqueza y vitalidad de la identidad nacional se basa en la diversidad étnica y cultural de México (Latapí I998: I73-I74). Sin embargo, estas afirmaciones se han quedado en el papel y no se han promovido medidas concretas para eliminar el racismo a través de la escuela, institución que, por su carácter de transmisor eficaz de ideologías, podría contribuir a la erradicación de actitudes racistas y discriminatorias en la sociedad.

\section{Conclusiones}

Aunque parezca que los libros escolares no forman parte de los discursos políticos, este análisis trae a la luz que los LTG mexicanos reflejan las ideologías de los gobiernos que los produjeron: de la perspectiva nacionalista de los primeros libros se pasa a una visión populista-tercermundista antes de moverse a una ideología neoliberal, como lo muestra la última generación de libros que analizamos. Estos libros y el entero sistema educativo mexicano han jugado un papel fundamental para la transmisión y reproducción de la ideología que está a la base de la identidad nacional. Esto es, los LTG han conformado un modelo cognitivo de mexicano en el que, por razones socio-políticas que aquí se han desarrollado, no se ha considerado al indígena.

se abrieron totalmente las fronteras para el ingreso de cualquier tipo de mercancías libres de todo gravamen y para la irrupción de inversión extranjera directa, libre de limitación fiscal y legal.

Sin embargo, los libros de texto emitidos en la reforma educativa de CSG, tergiversan y silencian estos hechos. Por ejemplo, Young (I998: s/n) denuncia que en el libro El hombre en la historia 3 elaborado a fines del sexenio de CSG «aplaude su programa Solidaridad, comentando que con él se reformó el concepto anterior de la Revolución Mexicana como un proyecto estadista de inversión, justicia y progreso dirigido hegemónicamente por el gobierno, para dar mayor participación a los individuos y empresas particulares [...] siendo que -para la mayoría de analistas críticos, dicho programa no benefició en nada a la mayoría de campesinos pobres y pequeños agricultores». Por lo que se refiere al enfoque que se le dio en los libros de texto al levantamiento zapatista, Young (I998: s/n) advierte que «[e]l retrato es comprensivo y evita toda crítica del Presidente [CSG]. No sólo omite la codicia, la corrupción y el autoritarismo de su sexenio, también lamenta que un hombre tan honesto y honorable tuviera que "sufri[r] varios reveses" como la rebelión zapatista. Aunque la mayoría de los intelectuales que estudian América Latina consideran que este movimiento fue un acontecimiento monumental en la historia reciente de México, el evento recibe apenas una frase en el texto, mismo que lamenta que sucediera». 
El indígena aparece en los materiales de I960 pero, a nivel verbal, es desagentivizado. De las seis ocasiones en que aparece, solo en una se le otorga voz y en el resto se presenta como paciente. Su representación, tanto icónica como verbal fomenta la idea del «indio» como antítesis del progreso y la civilización, y se le trata desde una posición paternalista deferente, de arriba hacia abajo. Esta figura es invisibilizada en las siguientes generaciones de libros, lo cual ha tenido repercusiones en la construcción ideológica de la representación grupal. En efecto, los LTG han jugado un papel primordial en la construcción y difusión del esquema de identidad mexicana y al no hacer mención de los pueblos indígenas los eliminan del MCI que representa el esquema de autorrepresentación colectiva. Esta omisión ha contribuido al desarrollo de una ideología racista y ha fomentado la discriminación hacia los pueblos indígenas.

Finalmente, concordamos con van Dijk (I997: 67) cuando dice que «si existe una situación en la que las cogniciones sociales se adquieren y se cambian es a través del discurso educativo", por tal razón podemos sostener que el sistema escolar sería una herramienta útil para erradicar los prejuicios raciales que silencian a los pueblos indígenas. Sin embargo, para lograr esto habría primero que, como afirma Latapí, revisar a fondo el proyecto de país y «descartar para siempre las fantasías modernizadoras, profundamente racistas, de los funestos gobiernos neoliberales» (Latapí I998: I74).

\section{Bibliografía:}

Atienza Cerezo, E. (2007). "Discurso e ideología en los libros de texto de ciencias sociales ». Discurso \& Sociedad I (4), 543-574.

Ávila, R. (coord.) (1984). Mi libro de primero. Parte I. México: Comisión Nacional de los Libros de Texto Gratuitos, SEP.

Ávila, R. (r984). Mi libro de primero. Parte II. México: Comisión Nacional de los Libros de Texto Gratuitos, SEP.

Benwell, B. \& Stokoe, E. (2006). Discourse and identity. Edinburgh: Edinburgh University Press.

Cabanel, P. (2007). Le Tour de la nation par des enfants. Romans scolairs et espaces nationaux (XIX-XX siècles). Paris, Berlin (coll. « Histoire de l'education $»$ ).

Caponi, O. \& Mendoza, H. (r997). «El neoliberalismo y la educación ». Acta odontológica venezolana 35, 26-33. 
Chapela Mendoza, L. M. (I994). Libro Integrado. Primer grado. México: Comisión Nacional de los Libros de Texto Gratuitos, SEP.

Chine, D. (20I I). "La Révolution mexicaine racontée aux enfants ». Caravelle 97. Toulouse: Presses Universitaires du Midi, I 5-30.

D’Alessandro, S. (20I4). "Las representaciones del pasado reciente en los textos escolares de Historia en Paraguay ». Discurso \& Sociedad 8 (I), 37-56.

de Fina, A. (2007). "Group identity, narrative and self-representations ", en A. de Fina, D. Schiffrin \& M. Bamberg (eds.), Discourse and Identity. New York: Cambridge University Press, 35 I-375.

Domínguez Aguirre, C. \& León González, E. (I960). Mi libro de primer año. México D. F.: Comisión Nacional de los Libros de Texto Gratuitos, SEP.

Domínguez Aguirre, C. \& León González, E. (I960). Mi cuaderno de trabajo de primer año. México D. F.: Comisión Nacional de los Libros de Texto Gratuitos, SEP.

García Aguirre, M. A. (2013). La situación actual de los pueblos y comunidades indígenas y negroafromexicanas de Oaxaca, Cuadernos Temáticos Populares. México: Secretaría de Asuntos Indígenas. Gobierno del Estado de Oaxaca.

Goffman, E. (I959). The Presentation of Self in Everyday Life. Harmondsworth: Penguin.

Gilbert, D. (2003). "Emiliano Zapata: Textbook Hero », Mexican Studies/ Estudios Mexicanos I9, I. University of California Press, Universidad Nacional Autónoma de México, University of California Institute for Mexico and the United States, I 27-I 59.

Kress, G. \& van Leewen, T. (2006) [I996]. Reading images. The grammar of visual design. New York: Routledge.

Lakoff, G. (I987). Women, fire and dangerous things: what categories reveal about the mind. Chicago: University Chicago Press.

Lakoff, G. \& Johnson, M. (I980). Metaphors We Live by. Chicago: University Chicago Press.

Latapí Sarre, P. (I998). Tiempo educativo mexicano V. México: Universidad Autónoma de Aguascalientes.

Lezama Juárez, G. (s/f) « La política exterior de Echeverría. ¿Continuidad o Ruptura? " Disponible en: https://www.academia.edu/I 5866658/La_pol\% $\mathrm{C}_{3} \%$ ADtica_exterior_de_Luis_Echeverr\% $3 \%$ ADa._Continuidad_o_ ruptura (Consultado I9.I I.I 8) 
Melgar Adalid, M. (I998). "Las reformas al artículo tercero constitucional », en J. García Díaz (ed.), Ochenta años de vida constitucional en México. México, Instituto de Investigaciones Jurídicas UNAM / Cámara de Diputados. LVII Legislatura. Comité de Biblioteca e Informática, 457-476.

Narvaja de Arnoux, E. (2008). Los discursos sobre la nación y el lenguaje en la formación del Estado (Chile, I 842-I 862). Estudio glotopolítico. Buenos Aires: Santiago Arcos Editor.

Navarrete Linares, F. (2008). Los pueblos indígenas de México, México, Comisión Nacional para el Desarrollo de los Pueblos Indígenas.

Oteíza, T. (20I4). "Intertextualidad en la recontextualización pedagógica del pasado reciente chileno ". Discurso \& Sociedad 8 (I), Io9-I 36.

Shapira, Y. (I978). "La política exterior de México bajo el régimen de Echeverría: Restrospectiva ». Foro Internacional XIX, I (73) julio-septiembre. El Colegio de México, 62-9I.

Rodríguez Gómez, D. (20I I). Viejos y nuevos racismos en los libros texto de ciencias sociales: El caso comparado de libros texto de la enseñanza media y secundaria en Colombia y Sudáfrica. Saarbrücken: Editorial Académica Española.

Rosch, E. (I978). " Principles of categorization », en E. Rosch \& B. B. Lloyd (eds.), Cognition and Categorization. Hillsdale, NJ: Lawrence, 27-48.

Taboada, M. B. (20II). Libros de texto e identidad profesional docente: Aportes desde una aproximación discursiva y crítica. Saarbrücken: Editorial Académica Española.

Tajfel, H. (I98I). Human Groups and Social Categories. Cambridge: Cambridge University Press.

Taylor, J. (I995). Linguistic categorization: prototypes in linguistic theory. Oxford: Clarendon Press.

Torres Barreto, A. (2007). Los libros de texto gratuitos de historia en la politica educativa de México 1959-I994, tesis de doctorado en historia. México: UNAM.

van Dijk, T. (I985). "Social cognition and discourse ", en H. Giles \& W. P. Robinson (eds.), Handbook of social psychology. Chichester: John Wiley \& Sons, I $63-\mathrm{I} 83$.

van Dijk, T. ( I 997). «Discurso, cognición y sociedad ». Signos. Teoría y práctica de la educación, 66-74.

van Dijk, T. (I998). Ideology. A Multidisciplinary Approach. London, Thousand Oaks, New Delhi: SAGE Publications. 
van Dijk, T. (2000). Ideology and Discourse. A multidisciplinary introduction. Universitat Oberta de Catalunya (UOC).

van Dijk, T. (2002). "Ideology: Political discourse and cognition », en P. Chilton \& C. Schäffner (eds.), Politics as text and talk: Analytical approaches to political discourse. Amsterdam: John Benjamins, 203-238.

van Dijk, T. (2008). Discourse and context. A sociocognitive approach. Cambridge: Cambridge University Press.

van Dijk, T. (20I I). Ideología y discurso. Barcelona: Ariel Lingüística.

Villa Lever, L. (1988). Los libros de texto gratuitos. La disputa por la educación en México. México: Universidad de Guadalajara.

Young, K. (I998). « Progreso, patria y héroes. Una crítica del currículo de historia en México ». New York: History Department, State University of New York.

Zullo, J. (20I4). «El golpe de Estado llega al aula. Las versiones para niños de la historia reciente ». Discurso \& Sociedad, 8 (I), I 2-36. 